\title{
Restructuring of user education programmes in university libraries from user perspectives: a case study
}

Hindagolla, B.M.M.C.B. ${ }^{1}$

\begin{abstract}
The study examines the effectiveness of the user education programmes offered by the main library of the University of Peradeniya, Sri Lanka. Attitudes of users towards the user education programmes conducted by the Library and their suggestions for the user centric user education program are discussed. A user survey was conducted for the study and undergraduates of the Faculty of Arts were selected as the target group. Results of the study discovered that the available library user education programs are inadequate to increase the awareness of all available information resources and services offered by the library. Strengths and weaknesses of the existing user education programs were discovered and further improvements are also suggested.
\end{abstract}

Keywords: User Education, Information Literary, Lifelong Learning, Sri Lanka

\section{Introduction}

Access to information is vital for the academic community to expand their knowledge, engage in research and drive towards lifelong learning. University Libraries have a prominent place within the academic sector to support teaching, learning and research of the university community. Hence, the university library has to play a major role to ensure the use of it's information resources, services and optimizing information requirements of the user population. The users have to be aware of the resources and services of the Library in order to get the optimum use of it.

World Bank (2009) discusses critical challengers that have been faced by the Sri Lankan university education sector in relation to the unemployment of graduates. According to

1 Hindagolla, B.M.M.C.B., Assistant Librarian, University of Peradeniya, Sri Lanka, Email: menakah@pdn.ac.lk 
Journal of the University Librarians Association, Sri Lanka, Vol. 16, Issue 1, January 2012

their analysis, national universities produce a large number of graduates every year, but the majority of them are unemployable due to the fact that they do not fit into the current job market. Currently, this is a major challenge for the university education system. This situation was created due to several reasons;

- Graduates with fewer capabilities are produced increasingly through external degree programs and distance learning programs.

- Poor attitude shown by the private sector towards students who graduate from national universities.

- Knowledge and skills of graduates need to be securely harnessed to fit the needs of the economy (World Bank, 2009).

Moreover, the World Bank (2009) indicates that Sri Lankan universities have to strengthen and bring the education system to an international standard. To fit with the current job market or current requirements of the country, university students must be able to identify and access current information and use information effectively (World Bank, 2009). This capability will help students become competent in their studies and research and also develop critical thinking. Moreover, it will lead towards lifelong learning which must be given priority in the current information-based societies. Therefore, to reach undergraduates up to this level, the university library has a major responsibility as part of this process. Hence, libraries have to find mechanisms to maximize using library resources and services. The library user education programs are the one mechanism of maximizing of library usage and able to aware users regarding library resources and services available at the library.

As limited studies, carried out at the University of Peradeniya for the sixty years of its existence, some studies found that users have a lack of awareness of the resources in main library. (Damayanthi, 2006; Darmarathana, 2008; Hindagolla, 2008) Those researches stressed the necessasity of well planned user education programs (UE programs) for the library to enhance information skills of undergraduates. As the largest library catering to largest undergraduate population of Sri Lanka, it is important to take 
Journal of the University Librarians Association, Sri Lanka, Vol. 16, Issue 1, January 2012

measures to enhance information skills of users and optimize utilization of resources and services offered by the library. This study looked into the user perception, requirements and views of the present day students and it will also produce an opportunity for students to suggest a new student-centered user education approach for the faculty of Arts.

\section{Contextual Background}

The University of Peradeniya library network is the largest University Library network in Sri Lanka, and the Main Library is the largest University Library in the University sector in Sri Lanka. It caters to 8000 users and it has become a main knowledge base for research in Social Sciences and Humanities in South Asia. The Main Library has been offering user education programmes to educate Library users for the last 30 years and offers three types of UE programmes; one hour Library introductory lecture, Library tour and distribute Library guides and handbooks. The Librarian or the Senior Assistant Librarian of Reader Services conducts a one hour lecture for the benefit of new entrants to the university and it covers basic information concerning the library, layout plan of the library, rules and regulations, Library membership procedures, how to access information, how to locate information, Library resources, services and facilities. Undergraduates of the Faculty of Arts participate in this programme during their faculty orientation period and the guided Library tour is to welcome students to the Library and give them a brief introduction to its physical layout, service points of the library facilities and services. At the end of the guided Library tour, leaflets are distributed to all the students. These pamphlets include instructions on how to use the catalog, instructions to various collections of books and resources available in the library, locations of materials and services, rules and regulations and privileges for the members. 
Journal of the University Librarians Association, Sri Lanka, Vol. 16, Issue 1, January 2012

\section{Aims of the Study}

This Study examined three research objectives.

1. To find out whether library user education programmes are geared towards making users aware of all kind of information resources, services available in the main library.

2. To find out the attitudes of users towards the user education programmes conducted by the main library.

3. To find out the user suggestions to improve user education programme conducted in the faculty of Arts.

\section{Research Method}

The study used survey research method. Total Undergraduate population of the Faculty of Arts was 2905. From the total population study sample stratified in to 339 undergraduates from all four years of faculty of Arts. To determine the sample Cochran (1977) sample frame was used and random sampling method was applied. A Questionnaire was used as the research instrument, to collect information for the study.

\section{Results and Discussion}

\section{Response Rate}

In this research, 339 questionnaires were distributed among the Undergraduates and 263 were duly returned. The response rate of the study was $77.58 \%$ and second year Undergraduates responded more than the other three years. $75.7 \%$ female and $24.3 \%$ of male undergraduates participated. A percentage of $77.21 \%$ of Sinhala medium, $68.51 \%$ Tamil medium and $89.58 \%$ of English medium Undergraduates responded. Undergraduates visit Main Library $74.90 \%$ daily and $22.05 \%$ of undergraduates visit Library weekly (two or three times a week) 
Undergraduates' participation in library user education programmes conducted by the Main Library.

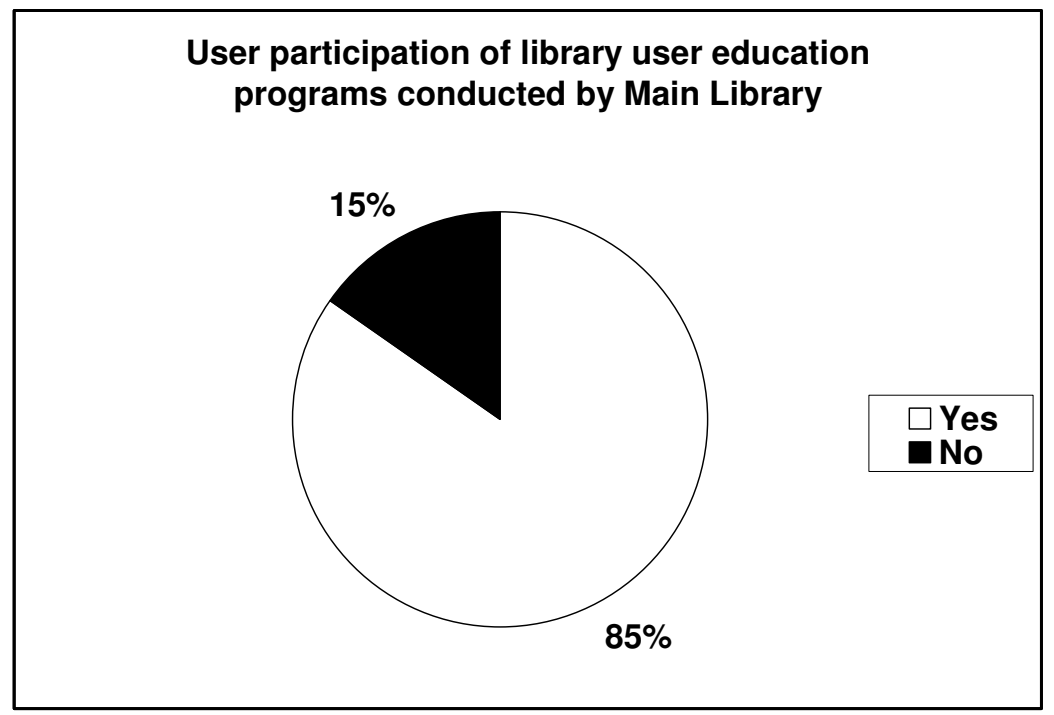

Figure 1: User participation in Library user education programmes

As shown in figure 1 , out of the total respondents $84.8 \%$ had participated in the library user education programs and $15.2 \%$ had not attended the program.

Table 1: Participation in library user education programmes according to the year

\begin{tabular}{l|llllll}
\hline Year & Participated & $\%$ & Not & $\%$ & Total & $\%$ \\
& \multicolumn{7}{|c}{ Participated } \\
\hline FirstYear & 78 & 84.78 & 14 & 15.22 & 92 & 100 \\
Second Year & 65 & 84.41 & 12 & 15.59 & 77 & 100 \\
Third Year & 46 & 86.79 & 7 & 13.21 & 53 & 100 \\
Fourth Year & 34 & 82.92 & 7 & 17.08 & 41 & 100 \\
& & & & & & 263 \\
\hline Total & $\mathbf{2 2 3}$ & & $\mathbf{4 0}$ & & & \\
\hline
\end{tabular}

Table 01 shows that among the Undergraduates, majority of third year Undergraduates participated in Llibrary user education programmes (86.79) compared to other categories. 
Journal of the University Librarians Association, Sri Lanka, Vol. 16, Issue 1, January 2012

Table 2: Participation in library user education programmes according to the medium of language

\begin{tabular}{l|llllll}
\hline Language & Partiapated & $\%$ & $\begin{array}{l}\text { Not Partici- } \\
\text { pated }\end{array}$ & Total & $\%$ \\
\hline English & 28 & 65.11 & 15 & 34.89 & 43 & 100 \\
Sinhala & 161 & 87.97 & 22 & 12.03 & 183 & 100 \\
Tamil & 34 & 91.89 & 3 & 8.11 & 37 & 100 \\
\hline & 223 & 84.79 & 40 & 15.20 & 263 & 100 \\
\hline
\end{tabular}

Table 2 shows the Undergraduate participation in library user education programmes according to their medium of language. Highest participation shows in Tamil medium (91.89\%) Undergraduates. Lowest participation (65.11\%) indicates English medium Undergraduates. It should be noted that the library user education programme is normally conducted during the orientation programme when the freshmen go through the English intensive course. Few students in English medium participate in the basic English program whereas, English medium students are exempted from these English courses therefore, a majority of students do not participate in the basic English programme. That factor could influence the low participation of English medium students for the library user programme.

\section{Awareness of Library Resources and Facilities}

Table 3 indicates the awareness received by Undergraduates in relation to Library resources at the library user education programs, Undergraduates mentioned that they received adequate awareness regarding Lending collection, Permanent Reference collection, Scheduled Reference collection and Sri Lanka collection. It is alarming fact that above $70 \%$ of Undergraduates did not receive any kind of awareness regarding special collections, e-journals and databases and audio visual materials. Undergraduates of the faculty of arts are still not aware about the above discussed special collections, e-journals and databases and audio visual materials. Due to limited allocated time for the 
Journal of the University Librarians Association, Sri Lanka, Vol. 16, Issue 1, January 2012 introductory lecture and the Library tour, it is not possible to cover every resource in the library and the description given at the orientation is not provide the users with adequate awareness, but the Library should find alternative methods to make library users aware of all the resources in the Library.

Table 3: Awareness of the library resources from the library user education programmes

\begin{tabular}{|c|c|c|c|c|c|c|c|c|c|}
\hline Resources & $\begin{array}{l}\frac{5}{5} \\
\frac{5}{5} \\
\frac{5}{8} \\
\frac{5}{8} \\
\frac{8}{8}\end{array}$ & ఫ్ఖ & 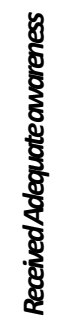 & de & 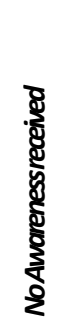 & de & $\begin{array}{l}\overline{8} \\
\overline{8} \\
\frac{8}{8} \\
\frac{8}{8} \\
\frac{0}{2}\end{array}$ & dீ & 要 \\
\hline Lending Collection & 212 & 80.6 & 10 & 3.8 & 1 & 0.3 & 40 & 15.2 & 263 \\
\hline PR Collection & 176 & 66.9 & 38 & 14.4 & 9 & 3.4 & 40 & 15.2 & 263 \\
\hline $\begin{array}{l}\text { Scheduled Reference } \\
\text { Collection }\end{array}$ & 136 & 51.7 & 63 & 23.5 & 24 & 9.1 & 40 & 15.2 & 263 \\
\hline SriLankaCollection & 184 & 69.9 & 33 & 12.4 & 6 & 2.2 & 40 & 15.2 & 263 \\
\hline $\begin{array}{l}\text { Periodicals (Current \& } \\
\text { Bound) }\end{array}$ & 124 & 47.1 & 78 & 29.6 & 21 & 7.9 & 40 & 15.2 & 263 \\
\hline Special Collections & 12 & 4.5 & 18 & 6.8 & 193 & 73.3 & 40 & 15.2 & 263 \\
\hline $\begin{array}{l}\text { E-resources(Access } \\
\text { toejournals) }\end{array}$ & 11 & 4.2 & 13 & 4.9 & 199 & 75.6 & 40 & 15.2 & 263 \\
\hline $\begin{array}{l}\text { AudioVisual } \\
\text { Materials }\end{array}$ & 1 & 0.38 & 4 & 1.5 & 218 & 82.8 & 40 & 15.2 & 263 \\
\hline
\end{tabular}

Relating to Library facilities and services Undergraduates had mentioned that they received proper awareness of lending facilities, reference facilities, over night reference book facilities, photocopying services, searching facility, OPAC and the internet facility which are available in the library. Although, library offers a number of services and facilities a majority of undergraduates were not aware about the inter-library loan 
Journal of the University Librarians Association, Sri Lanka, Vol. 16, Issue 1, January 2012

service, new book reserving facility, check slips facility, searching facility and the audio and CD ROMs services (see table 4). It is note that according to the above table, the Library user education programme did not prove adequate awareness of all the services and facilities which are offered by the Main Library. This directly influenced Undergraduates' usage level of the Library resources and services.

Table 4: Awareness received, library facilities from the library user education programmes

\begin{tabular}{|c|c|c|c|c|c|c|c|c|c|}
\hline Facilities \& Senvices & $\begin{array}{l}y \\
\frac{8}{5} \\
\frac{5}{5} \\
\frac{5}{4} \\
\frac{5}{5} \\
\frac{5}{8} \\
\frac{8}{4}\end{array}$ & do & 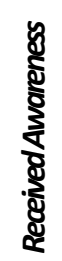 & do & 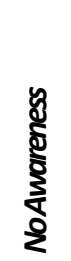 & dீ & $\begin{array}{l}\overline{8} \\
\frac{8}{8} \\
\frac{8}{8} \\
\frac{8}{8} \\
\frac{8}{2}\end{array}$ & de & $\begin{array}{l}\overline{8} \\
\text { 음 }\end{array}$ \\
\hline LendingFacility & 212 & 80.6 & 10 & 3.8 & 1 & 0.38 & 40 & 15.2 & 263 \\
\hline ReferenceFacility & 176 & 66.9 & 38 & 14.4 & 9 & 3.4 & 40 & 15.2 & 263 \\
\hline $\begin{array}{l}\text { Overnight reference book } \\
\text { Facility }\end{array}$ & 136 & 51.7 & 63 & 23.9 & 24 & 9.1 & 40 & 15.2 & 263 \\
\hline Inter libraryloan Senvice & 3 & 1.1 & 3 & 1.1 & 217 & 82.5 & 40 & 15.2 & 263 \\
\hline Newbooks resenvingFacility & 20 & 7.6 & 3 & 1.1 & 200 & 76.0 & 40 & 15.2 & 263 \\
\hline $\begin{array}{l}\text { Chedk Slips Facility (book } \\
\text { finding) }\end{array}$ & 46 & 17.4 & 4 & 1.5 & 173 & 65.7 & 40 & 15.2 & 263 \\
\hline DownloadingFacility & 101 & 38.4 & 16 & 6.0 & 106 & 40.3 & 40 & 15.2 & 263 \\
\hline Photocopying Service & 220 & 83.6 & 2 & 0.76 & 1 & 0.38 & 40 & 15.2 & 263 \\
\hline Searching Facility & 145 & 55.1 & 20 & 7.6 & 58 & 22.0 & 40 & 15.2 & 263 \\
\hline OPAC & 150 & 57.0 & 52 & 19.7 & 21 & 7.9 & 40 & 15.2 & 263 \\
\hline Audio and CDROMs & 2 & 0.76 & 4 & 1.5 & 217 & 82.5 & 40 & 15.2 & 263 \\
\hline IntemetFadilty & 137 & 52.0 & 32 & 12.1 & 54 & 20.3 & 40 & 15.2 & 263 \\
\hline
\end{tabular}




\section{User Attitudes towards Library User Education Programmes}

This study examined the perceptions of users regarding Library user education programme. Respondents were asked whether participating in Library user education programme was helpful for their learning and research process. A majority of respondents (70.3\%) agreed that participation of Library user education programme was useful to their learning and research process. It is note that Undergraduates have realized to a certain extend that the participate in Library user education is useful to their studies.

Table 5: User satisfaction with regard to current user education programmes they attended

\begin{tabular}{l|lc}
\hline UserSatisfaction & Frequency & $\%$ \\
\hline HighlySatisfied & 0 & 0 \\
Satisfied & 91 & 34.6 \\
Noidea & 24 & 9.12 \\
Unsatisfied & 104 & 39.5 \\
Highly Unsatiffied & 4 & 1.5 \\
NotAttend & 40 & 15.2 \\
\hline Total & & 100.0 \\
\hline
\end{tabular}

\section{Factors for Dissatisfaction}

Research findings in table 5 shows that a majority of respondents are not satisfied with the existing Library user education programmes. Based on the respondents' answers, nine factors were identified. The following table described reasons for user dissatisfaction regarding the Library user education programmes. Table 6 shows the according to the highest responses given by the Undergraduates. 
Journal of the University Librarians Association, Sri Lanka, Vol. 16, Issue 1, January 2012

Table 6: Reasons for user dissatisfaction regarding the library user education programmes

\begin{tabular}{c|llc}
\hline No & Reason & $\begin{array}{l}\text { Number } \\
\text { Respondents }\end{array}$ & of \\
\hline 1 & Thetimewas not the best time to offer program & 98 & 43.94 \\
2 & $\begin{array}{l}\text { Awareness given about e- resources and the internet were not } \\
\text { sufficient }\end{array}$ & 98 & 43.94 \\
3 & Less Practical & 97 & 43.49 \\
4 & Theareascovered in the program is not sufficient & 96 & 43.04 \\
5 & Largenumber ofstudents and lessattentiongiven to individuals & 96 & 43.04 \\
6 & Informationgiven in the program is notsufficient & & 40.80 \\
7 & Duration of the program is too short & 91 & 39.46 \\
9 & The language barrier & 88 & 16.59 \\
11 & Mode of instruction is not appropriate & 37 & 9.41 \\
\hline
\end{tabular}

The Main Library offers library user education programmes during the first year orientation period, according to the responses, that time is not physically and mental comfortable for the first year Undergraduates because after school education, students enter the University which is different type of education center than secondary schools. With that environment Undergraduates take time to get used to the University environment. Therefore, they might not get the maximum use of information given at the Library user education programme. They felt that one hour Library orientation lecture and the one hour library tour is not enough to cover areas at the library and less practical is not give proper training of library use to Undergraduates. Information delivered to a large number of students at a onetime does not achieve the objectives of the programme. 


\section{Suggestions to Improve Library User Education Programmes from the Users Perspective}

The study examined the user suggestions to improve the existing Library user education programmes. Majority of respondents $(83.6 \%)$ agreed that the current user education programmes should be modified. Because Undergraduates identified current programme does not meet the user information requirements.

When analyzing Undergraduates preferred methods of Library user education programmes according to their years, figure 2 indicates differences between years. According to the above graph very low response is given by the first year Undergraduates compared to third year and fourth year Undergraduates. Third year and fourth year Undergraduates who are familiar with the main library and the library resources and services than first years, similarly they have been realized the necessity of Library education and its services compared to first years. It is further confirmed that above $80 \%$ of Undergraduates of fourth years given their priority to Library tours, Credit course in the curricular, Small group instruction with practical experiences, Library guides and handbooks, Introductory lecture in the orientation programme. This shows according to the year of the study undergraduates have experienced user education should be more focused and a concerned factor of Undergraduate education. 


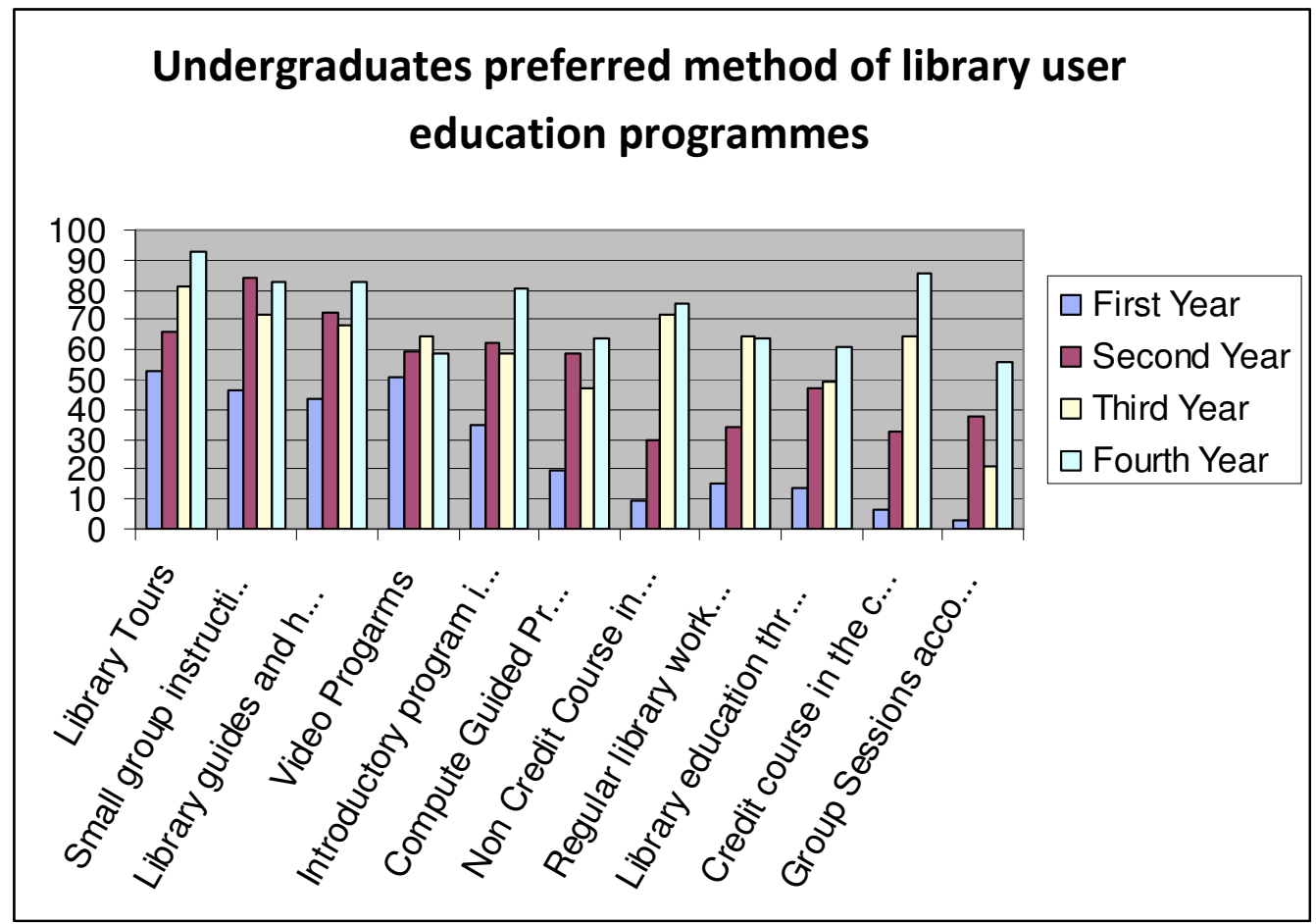

Figure 2: Undergraduates preferred methods for library user education program by year

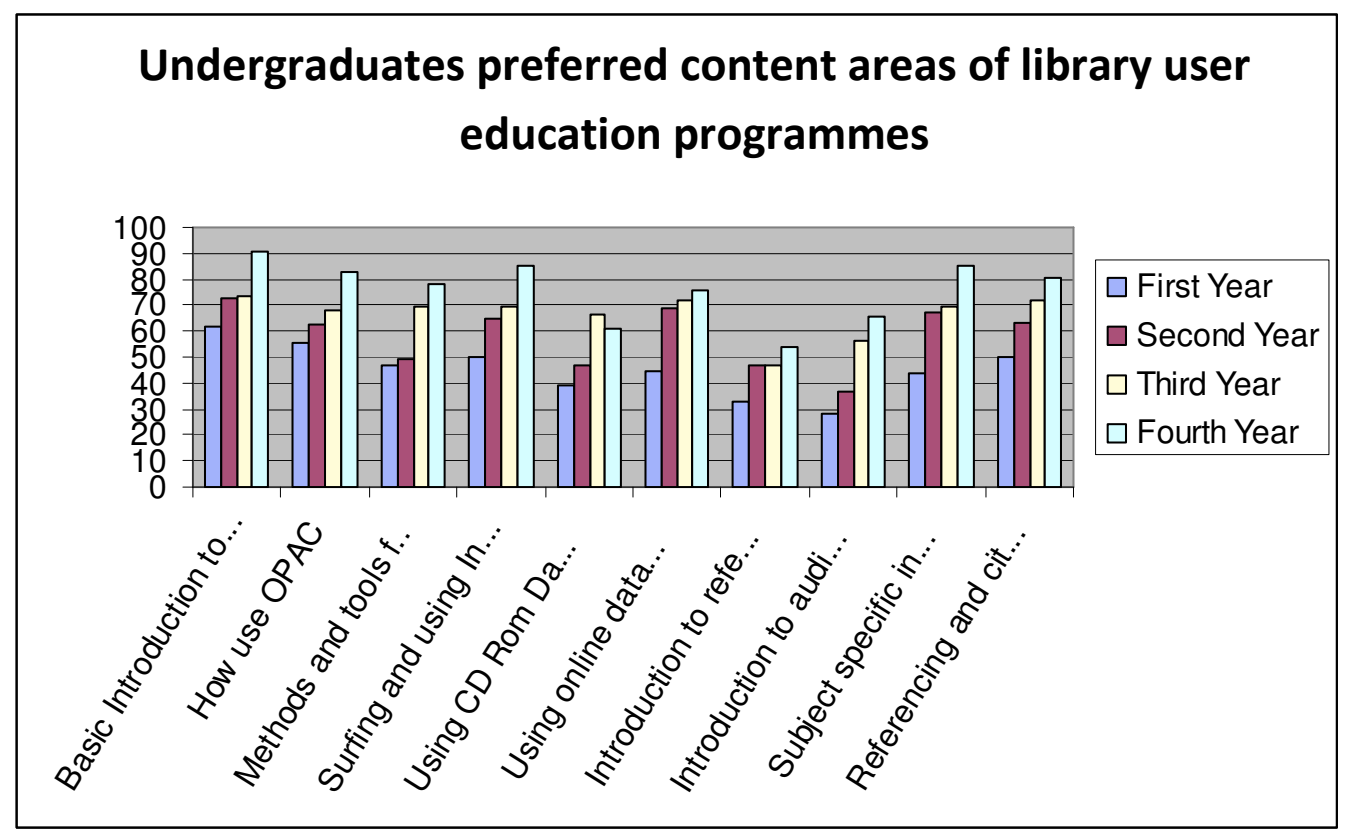

Figure 3: Undergraduates preferred content areas to learn from the library user education programmes by year 
Journal of the University Librarians Association, Sri Lanka, Vol. 16, Issue 1, January 2012

According to undergraduates responses above $50 \%$ of respondents would like to learn areas such as basic Introduction to library services and facilities, How use OPAC, Basic Introduction to library services and facilities, Methods and tools for searching information resources, Surfing and using Internet, Using CD Rom Databases, Using online databases and electronic journals, Subject specific information searching skills and Referencing and Citation in the library user education programs and majority of fourth year undergraduates (over 70\%) mentioned that they would like to have Basic Introduction to library services and facilities, How to use the Open Public Access Catalog, Using online databases and electronic journals, Subject specific information searching skills, Referencing and Citation, because fourth year undergraduates are preparing their research projects and they meet with difficulties in finding information for their academic work. Therefore, majority of fourth year undergraduates are willing to learn more content areas than other categories.

\section{Suggestions of Undergraduates to Improve Current Library User Education Programmes}

Respondents were given open ended questions to present their suggestions and comments to improve the Library user education programmes in future, they have given suggestions, comments to improve the effective and efficient Library user education programmes at Main Library, University of Peradeniya. The respondents had made one or more comments. The suggestions were arranged and organized under 10 statements as shown in table 6.

According to the Undergraduates comments majority of respondents (80.22\%) suggested that "Library user education programmes should continue all four years". Current Library user education programmes conduct for first years but user expectation is that the user education programme should be continues through four years. Further $60.07 \%$ stated that programme should not conduct during the orientation programme. 
Journal of the University Librarians Association, Sri Lanka, Vol. 16, Issue 1, January 2012

Table 06: Undergraduates suggestions to improve the library user education

\section{Programmes}

\begin{tabular}{|c|c|c|c|}
\hline No & Comments & Frequency & $\%$ \\
\hline 1 & Library user education programme should continue all four years & 211 & 80.22 \\
\hline 2 & $\begin{array}{l}\text { Library orientation programme should not conduct during the English } \\
\text { program. }\end{array}$ & 158 & 60.07 \\
\hline 3 & Additional lessons should be conduct in semester basis & 142 & 53.99 \\
\hline 4 & Content of the program should be moreelaborate & 138 & 52.47 \\
\hline 5 & Programme should conduct in all three languages & 130 & 49.42 \\
\hline 6 & Should library resources, senvices and facilities be more published & 124 & 47.14 \\
\hline 7 & Programme should conduct with practical & 117 & 44.48 \\
\hline 8 & Programme should cover subject specific information & 108 & 41.06 \\
\hline 9 & Should be introduce and promote information searching methods & 102 & 38.76 \\
\hline 10 & Libraryeducation will be more effective as a non credit course & 101 & 38.40 \\
\hline 11 & Libraryeducation should be incorporate to thestudy programme & 100 & 38.02 \\
\hline 12 & Programme should be proper order & 98 & 37.26 \\
\hline 13 & $\begin{array}{l}\text { Need more advanced specific information searching for research } \\
\text { conductingstudents }\end{array}$ & 58 & 22.05 \\
\hline
\end{tabular}

Above $50 \%$ of Undergraduates suggested that content areas covered in the user education programmes should be more elaborate and they expect additional lessons about the Library education in semester basis. Above $40 \%$ of respondents commented that they expect subject specific information with practical basis, programme in three languages and proper awareness of Library resources, facilities and services from Library user education programme. According to Undergraduates comments Library user education programme should be conduct in order, introduce and promote information searching methods. Further, about $30 \%$ of respondents would like to have a non credit course and Library education incorporate to study programme. Respondents were given 
Journal of the University Librarians Association, Sri Lanka, Vol. 16, Issue 1, January 2012

indication; they expect more advanced specific information for researchers. They suggested specific sessions should be included to the Library education for targeting researchers.

\section{Conclusion}

Although the Main Library at the University of Peradeniya offers Library user education programmes, these programmes do not provide proper awareness of Library resources and services which are available at the Main Library. Respondents strongly believed that current user education programmes should be modified according to the user current requirements. This Study identified that there is a gap between Undergraduates' expectation of Library user education programmes and what the Main Library offers. Undergraduates provide suggestions that Library should transfer from user education to more advanced in complexity with identifying Undergraduates current information requirements and to cater in different degrees.

\section{References}

Cochran, W.G.(1977). Sampling Techniques. ( $3^{\text {rd }}$ ed.). New York: John Wiley \& Sons.

Damayanthi, N. (2006). An assessment of electronic information resources usage and Management : a case study at University of Peradeniya, (Unpublished MLS thesis). Faculty of Graduate studies, University of Colombo.

Dharmarathna, A.(2008). Electronic Information resources : do the undergraduate reap the benefits of information communication technology. In U. Dissanayake (Ed.), Proceedings of the Peradeniya University research sessions, 3(1). (pp. 30-31). Peradeniya: University of Peradeniya.

Hindagolla, M.(2008). An Evaluation of use of the Ceylon Collection, Main Library University of Peradeniya for academic research advancement of Sri Lanka, In: In U. Dissanayake (Ed.), Proceedings of the Peradeniya University research sessions, 3(1). (pp. 32-33). Peradeniya: University of Peradeniya.

World Bank.(2009). The Towers of learning: performance, peril and promise of higher education in Sri Lanka. Colombo: The World Bank Colombo Office. 